\title{
Unusual oral presentation of acyclovir-resistant herpes simplex in an allogeneic haematopoietic stem cell transplant recipient
}

\author{
Thomas Saunsbury, Molly Harte, Daniela Ion
}

Department of Oral Medicine, Royal National ENT and Eastman Dental Hospital, University College London Hospitals, London, UK

\section{Correspondence to} Thomas Saunsbury; thomas.saunsbury@nhs.net

Accepted 29 November 2021

\section{SUMMARY}

The early engraftment phase of allogeneic haematopoietic stem cell transplantation can be associated with a number of oromucosal infective complications. While the routine use of prophylactic acyclovir has reduced the incidence of herpes simplex virus (HSV) reactivation, there is an increasing prevalence of acyclovir resistance within this cohort of patients. The authors present a case of acyclovir-resistant HSV reactivation in a 26-year-old woman 7 days post T-deplete sibling allograft on a background of combined cyclophosphamide and total body irradiation myeloablative conditioning, successfully treated with foscarnet and cidofovir therapy and discuss the differential diagnoses for early/late engraftment oral disease.

\section{BACKGROUND}

Haematopoietic stem cell transplantation (HSCT) is a potentially curative treatment option for the management of haematological malignancy, and non-malignant haematological dyscrasiasincluding myelodysplastic disorders and haemoglobinopathies. From an oral perspective, HSCT can be associated with both acute and chronic complications, either secondary to pre-engraftment conditioning regimens or directly resulting from transplant. ${ }^{1}$

Acute oral complications are seen in up to $70 \%$ of patients receiving HSCT and include oral mucositis, graft-versus-host disease (GvHD) and infection. The incidence of oral mucositis is in the region of $73 \%-86 \%,{ }^{2}$ with the severity of its presentation directly correlated to the intensity of the conditioning regimen implemented. The incidence of severe mucositis (WHO Oral Mucositis Grading Scale II-IV) is higher in patients receiving total body irradiation (TBI), ${ }^{3}$ however, other determinants such as the use of methotrexate in GvHD prophylaxis have also been identified. ${ }^{4}$

GvHD is a common complication of HSCT and remains a leading cause of non-relapse posttransplant mortality. Acute GvHD is reported in up to $50 \%$ of HSCT recipients with human leucocyte antigen (HLA) mismatch, a well-documented risk factor for its development. ${ }^{5}$

Post-HSCT infection is the leading cause of post-transplant morbidity in the pre-engraftment, immediate and late postengraftment periods, with a number of transplant factors influencing immune reconstitution-HLA disparity, $T$ cell depletion,

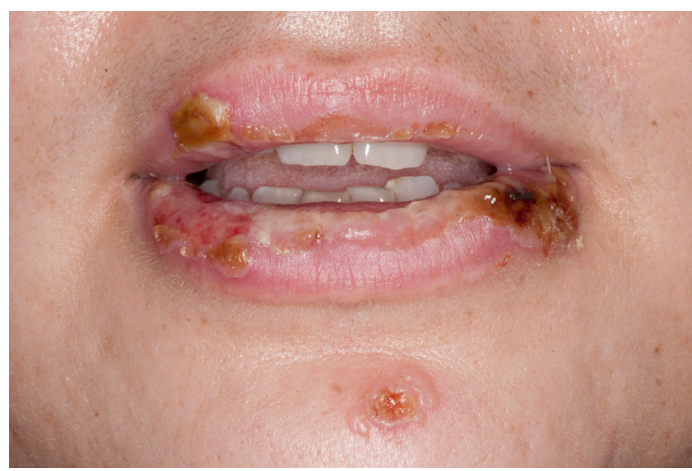

Figure 1 Pretreatment perioral HSV presentation.

GvHD. ${ }^{6}$ Pre-engraftment is characterised by aplasia, with recovery of neutrophil counts by week 2-3. The postengraftment immunodeficient state is secondary to reduced number of natural killer cells of the innate immune system and T cells of the adaptive immune system, which can take up to 24 months to normalise. ${ }^{7}$

The combination of neutropenia and disrupted mucosal barrier protection, secondary to mucositis, in the early pre-engraftment period is associated with a high risk of HSV infection. Reactivation was seen in up to $80 \%$ of HSV-seropositive HSCT recipients prior to the introduction of routine antiviral prophylaxis. Routine prophylactic use of acyclovir following allogeneic HSCT has reduced the incidence of HSV reactivation to $0 \%-3 \% .^{8}$ The recent emergence of acyclovir-resistant HSV, particularly among immunocompromised patients, poses a challenge in the acute management of HSCT patients postengraftment.

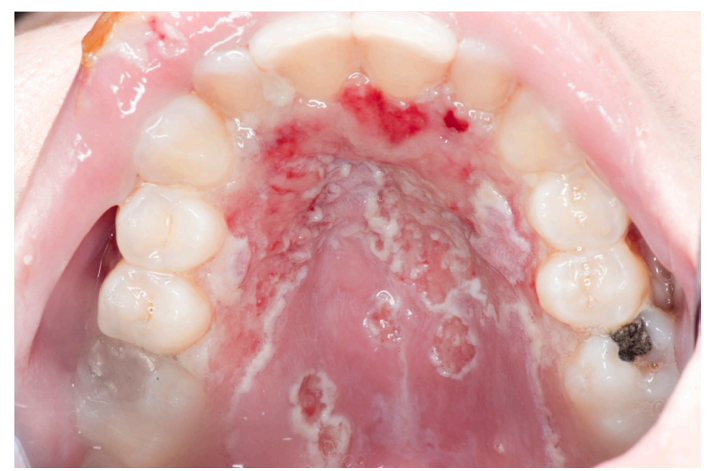

Figure 2 Bilateral erosive disease of the hard palate. 


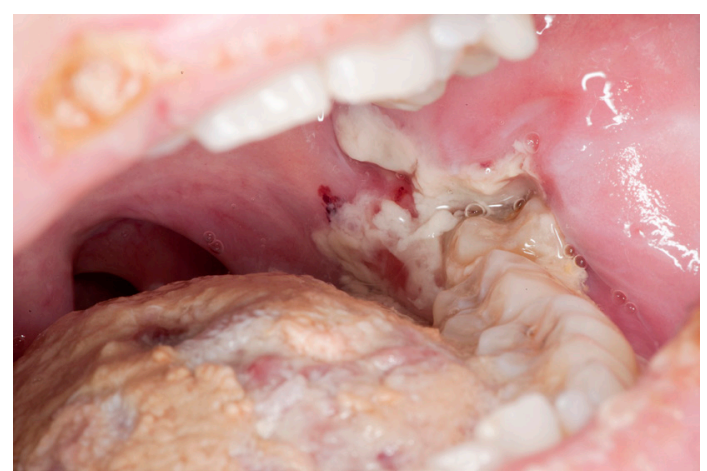

Figure 3 Fibrinous pseudomembrane of retromolar trigone.

\section{CASE PRESENTATION}

A 26-year-old woman diagnosed with myelodysplastic syndrome with multi-lineage dysplasia received a T-deplete sibling allograft on a background of combined cyclophosphamide and TBI myeloablative conditioning. She was referred to the oral medicine department secondary to the onset of oral ulceration which developed day 7 postengraftment. As per protocol, the patient was receiving prophylactic oral acyclovir $(200 \mathrm{mg}$, three times a day) at this stage.

Examination revealed diffuse irregular ulceration of the keratinised and non-keratinised oromucosae, with no dermatomal confinement. Extensive pseudomembranous cover was noted, with no diffuse mucosal atrophy or suggestion of underlying lichenoid phenotype. There was no noted oropharyngeal involvement, or haemorrhagic crusting to the lip prolabia pathognomonic of erythema multiforme. A single concentric crusted lesion was noted in the mental region (figures 1-4). In terms of wider mucocutaneous involvement, there was a large blister of the left dorsal foot and an acneiform rash of the back and shoulder.

\section{INVESTIGATIONS}

PCR swab testing of the oral ulceration was positive for HSV-1 and excluded Epstein-Barr Virus, Varicella Zoster Virus and Cytomegalovirus.

HSV-1 drug resistance testing was carried out and demonstrated HSV-1 UL23 mutation, associated with acyclovir resistance.

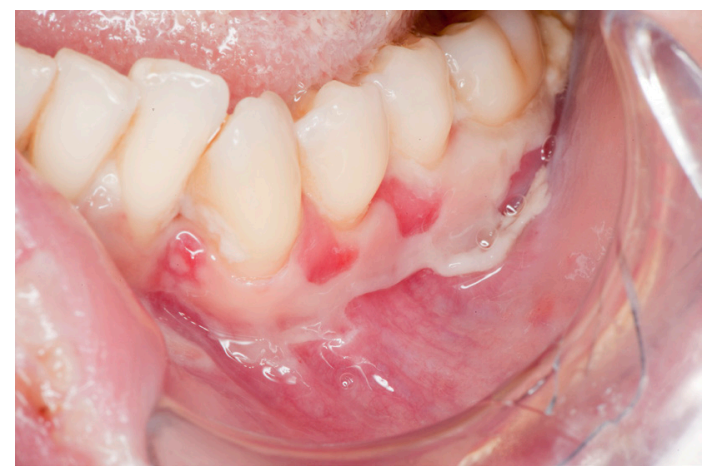

Figure 4 Superficial erosion of the attached mandibular gingivae.

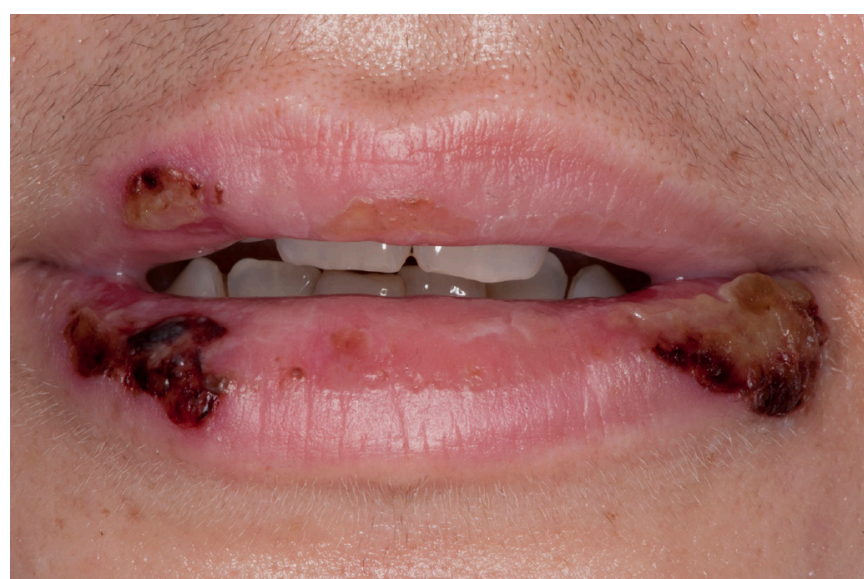

Figure 5 Evident healing of vermillion ulceration following escalation of intravenous acyclovir to treatment dose.

\section{DIFFERENTIAL DIAGNOSIS}

Differential diagnosis at initial presentation included erythema multiforme secondary to HSV-1, paraneoplastic autoimmune multiorgan syndrome (PAMS) and HSV-1 recrudescence.

Viral reactivation occurs frequently following HSCT and given the extensive oral ulceration, crusting of the lips and concentric lesion of the chin, erythema multiforme secondary to HSV-1 reactivation was the first diagnosis considered. The lack of classical cutaneous 'target' lesions and the failure of the oral symptoms to self-resolve made this diagnosis less likely.

In combination with the history of blistering of the left dorsal foot, the suspicion of PAMS was raised following the failure of improvement seen with initial treatment dose intravenous antiviral therapy. A close haematology-oncology review was carried out and confirmed successful graft, negating this possible diagnosis.

The final diagnosis reached was HSV-1 recrudescence. This was initially considered somewhat unlikely given both the severe presentation and concomitant antiviral prophylaxis. In view of this differential, HSV-1 drug resistance testing was carried out and demonstrated HSV-1 UL23 mutation, associated with acyclovir resistance.

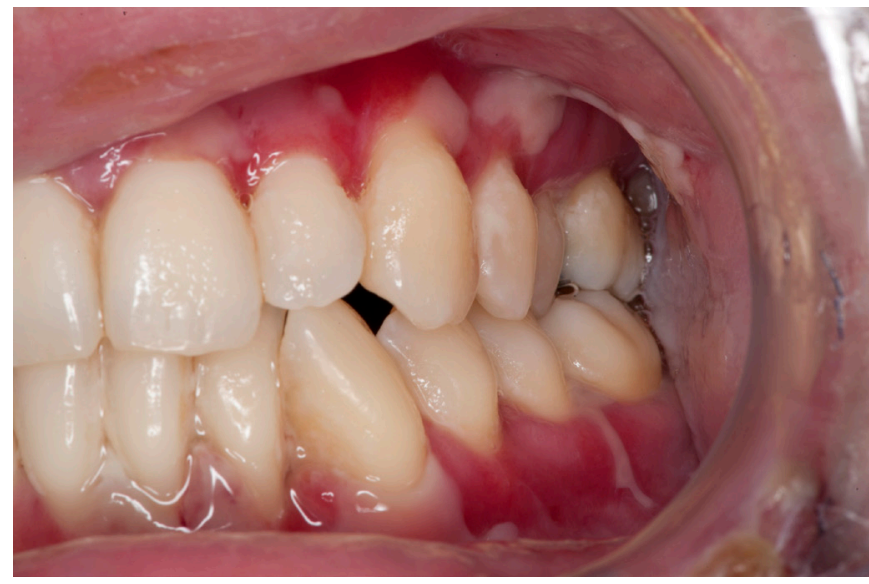

Figure 6 Limited intra-oral clinical improvement following escalation of intravenous acyclovir to treatment dose. 


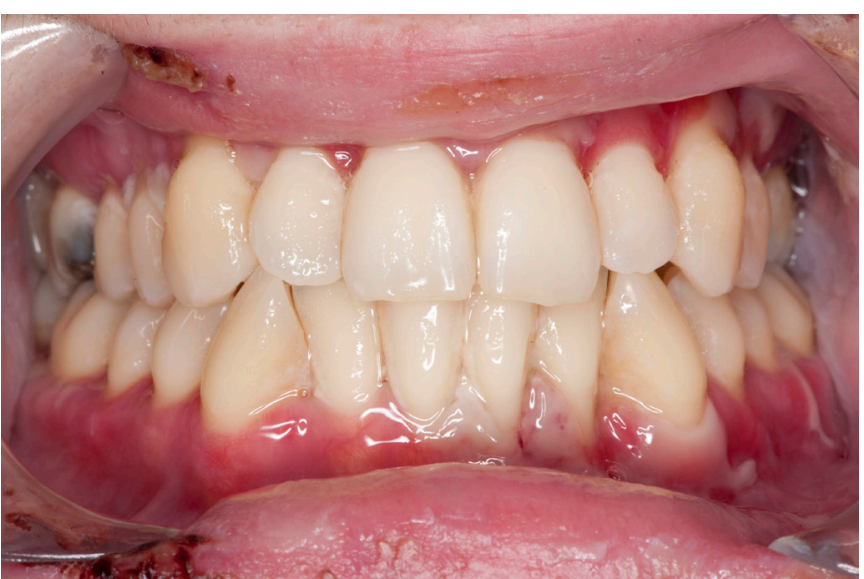

Figure 7 Limited intra-oral clinical improvement following escalation of intravenous acyclovir to treatment dose.

\section{TREATMENT}

Prior to HSV-1 drug resistance testing, treatment was escalated to intravenous treatment dose acyclovir $(10 \mathrm{mg} / \mathrm{kg}$ three times a day) for 10 days, with partial clinical response (figures 5-7). Subsequent switch to oral valacyclovir $(500 \mathrm{mg}$ two times per day) resulted in rebound disease activity.

The limited disease modifying action of acyclovir and analogues was later attributed to HSV-1 UL23 mutation acyclovir resistance. Cross-resistance was suggested by the limited improvement with foscarnet therapy $(90 \mathrm{mg} / \mathrm{kg}$ three times a day). Substitution for intravenous cidofovir ( $375 \mathrm{mg}$ ) once weekly for 4 weeks resulted in complete remission of oral ulceration (figures 8-10). The patient was then returned to oral acyclovir ( $400 \mathrm{mg}$ three times a day) as per routine prophylaxis guidelines.

\section{OUTCOME AND FOLLOW-UP}

- At 3-month review, there was no evidence of mucosal activity, with stable oromucosal appearances.

\section{DISCUSSION}

The antiviral action of acyclovir results from its selective phosphorylation by the viral enzyme, thymidine kinase. The resultant triphosphate metabolite is a competitive inhibitor for viral DNA polymerase, resulting in viral inactivation and DNA chain termination. ${ }^{9}$ Resistance derives from mutations to either DNA polymerase

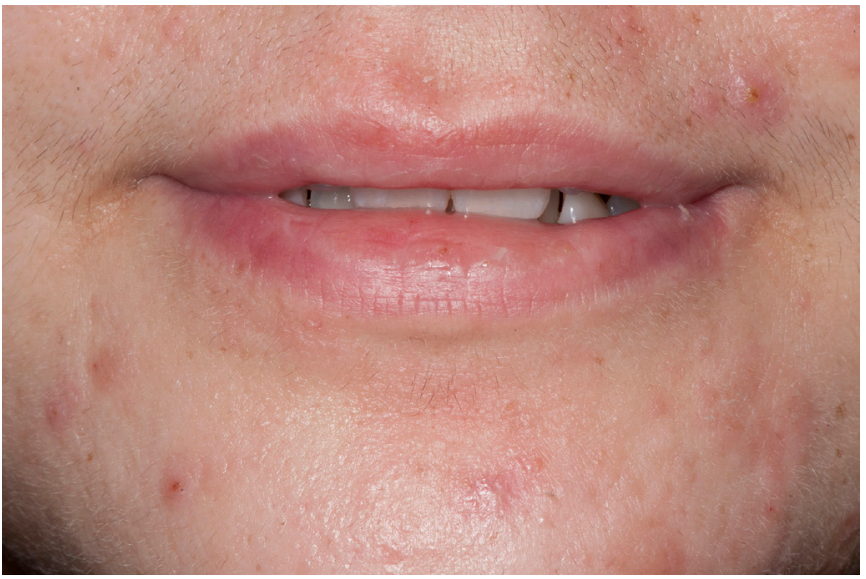

Figure 8 Perioral healing secondary to 3-week course of intravenous cidofovir ( $5 \mathrm{mg} / \mathrm{kg}$, once weekly).

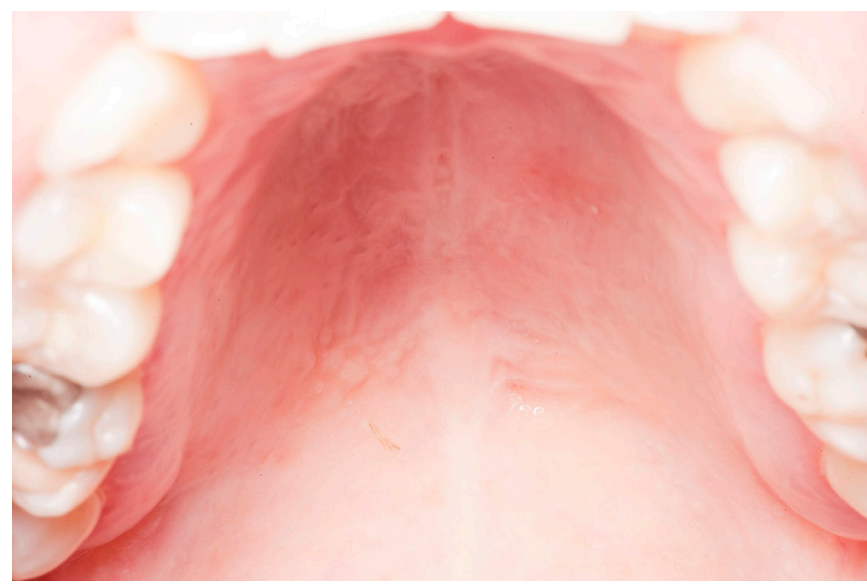

Figure 9 Clinical appearance of hard palate post-3-week course of intravenous cidofovir ( $5 \mathrm{mg} / \mathrm{kg}$, once weekly).

or the thymidine kinase enzyme-with three distinct phenotypes identified in terms of TK activity-absent, reduced or altered. ${ }^{10}$ Unlike acyclovir, cidofovir and foscarnet do not require enzymatic phosphorylation and act as direct inhibitors/alternative substrates for HSV DNA polymerase-thus are effective second-line agents in treating acyclovir-resistant isolates.

Literature review demonstrates a prevalence of acyclovir resistance of $14 \%-46.5 \%$ within HSCT recipients with clinically confirmed HSV infection, ${ }^{11-13}$ — which is markedly higher than in immunocompetent patients. Concomitant GvHD is reported to be an additional significant risk factor for the development of antiviral resistance. $^{14}$

This case report demonstrates successful treatment of HSV resistance with both cidofovir and foscarnet, however, there are case reports of cross-resistance to acyclovir and foscarnet. ${ }^{15}$ Escalation to cidofovir in this isolated example has proven clinically effective. ${ }^{16}$ Both medications show a similar adverse side effect profile in terms of nephrotoxicity.

Risk factors for infection postallograft are multifactorial—relating to impaired innate and acquired immune responses. These include the underlying host disease, type of conditioning regime implemented, the type of graft and presence/absence of GvHD. ${ }^{17}$ In this case, infection occurred in the early engraftment phase ( $<30$ days), with evident neutropenia and disruption of mucosal barriers underlying susceptibility. Both acute leukaemia and myelodysplastic syndrome as underlying host diseases result in profound preallograft

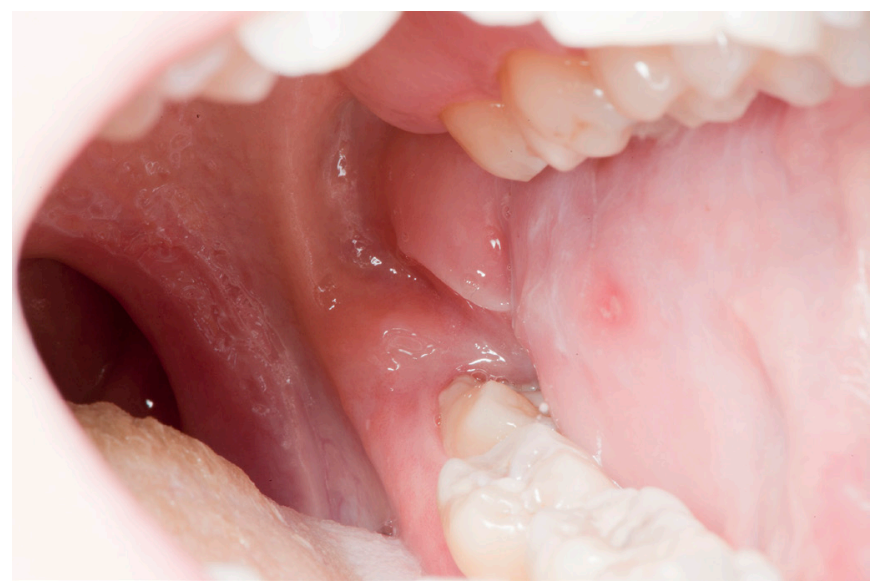

Figure 10 Clinical appearance of retromolar trigone secondary to 3-week course of intravenous cidofovir ( $5 \mathrm{mg} / \mathrm{kg}$, once weekly). 
neutropenia and risk factors for infection. The myeloablative conditioning regimens used in this case, with cytotoxic chemotherapy and TBI, result in mucositis and neutropenia which further exacerbate the risk of infection over reduced intensity regimens. ${ }^{18}$ HLA matching is also a contributory factor to the development of GvHD and risk of superinfection.

\section{Learning points}

- An understanding of conditioning regimens and the timeline of immune reconstitution can aid clinicians in identifying likely causes of acute and/or chronic complications in haematopoietic stem cell transplantation (HSCT) patients during these distinct clinical phases.

- Despite routine antiviral prophylaxis regimens post-HSCT, viral recrudescence should be considered in cases of oromucosal ulceration due to increasing resistance.

- Prodromal phenomena, irregular lesion borders and vesicular phenotype are often diagnostic features of viral ulceration. Direct methods for specimen collection of suspected herpes simplex virus lesions include de-roofing of vesicles and use of a Rayon swab, rotated firmly of the lesion base. For older lesions, the Tzanck test can be used for diagnosis, by scraping the base of the lesion with the edge of a scalpel blade.

Acknowledgements UCLH Haematology Department, Dr Ben Carpenter and Dr Arian Laurence, for their care of the study patients.

Contributors TS is responsible for the overall content of this report as guarantoraccepting full responsibility for the finished work and/or the conduct of the study, access to the data, and control of the decision to publish. MH and DI have been instrumental in the planning, conduct and reporting of the work described in this article.

Funding The authors have not declared a specific grant for this research from any funding agency in the public, commercial or not-for-profit sectors.

Competing interests None declared.

Patient consent for publication Consent obtained directly from patient(s).

Provenance and peer review Not commissioned; externally peer reviewed.

Case reports provide a valuable learning resource for the scientific community and can indicate areas of interest for future research. They should not be used in isolation to guide treatment choices or public health policy.

\section{REFERENCES}

1 Haverman TM, Raber-Durlacher JE, Rademacher WMH, et al. Oral complications in hematopoietic stem cell recipients: the role of inflammation. Mediators Inflamm 2014;2014:1-18

2 Chaudhry HM, Bruce AJ, Wolf RC, et al. The incidence and severity of oral mucositis among allogeneic hematopoietic stem cell transplantation patients: a systematic review. Biol Blood Marrow Transplant 2016;22:605-16.

3 Sonis S, Antin J, Tedaldi M, et al. Snp-based Bayesian networks can predict oral mucositis risk in autologous stem cell transplant recipients. Oral Dis 2013;19:721-7.

4 Cutler C, Li S, Kim HT, et al. Mucositis after allogeneic hematopoietic stem cell transplantation: a cohort study of methotrexate- and non-methotrexate-containing graft-versus-host disease prophylaxis regimens. Biol Blood Marrow Transplant 2005;11:383-8.

5 Lazaryan A, Weisdorf DJ, DeFor T, et al. Risk factors for acute and chronic graft-versushost disease after allogeneic hematopoietic cell transplantation with umbilical cord blood and matched sibling donors. Biol Blood Marrow Transplant 2016;22:134-40.

6 Sahin U, Toprak SK, Atilla PA, et al. An overview of infectious complications after allogeneic hematopoietic stem cell transplantation. J Infect Chemother 2016:22:505-14.

7 Ogonek J, Kralj Juric M, Ghimire S, et al. Immune reconstitution after allogeneic hematopoietic stem cell transplantation. Front Immunol 2016;7:507.

8 Lin R, Liu Q. Diagnosis and treatment of viral diseases in recipients of allogeneic hematopoietic stem cell transplantation. J Hematol Oncol 2013;6:94.

9 Kimberlin DW, Whitley RJ. Antiviral resistance: mechanisms, clinical significance, and future implications. J Antimicrob Chemother 1996;37:403-21.

10 Crumpacker CS, Schnipper LE, Marlowe SI, et al. Resistance to antiviral drugs of herpes simplex virus isolated from a patient treated with acyclovir. N Engl J Med 1982;306:343-6.

11 Kakiuchi S, Tsuji M, Nishimura H, et al. Association of the emergence of acyclovirresistant herpes simplex virus type 1 with prognosis in hematopoietic stem cell transplantation patients. J Infect Dis 2017;215:865-73.

12 Anton-Vazquez V, Mehra V, Mbisa JL, et al. Challenges of aciclovir-resistant HSV infection in allogeneic bone marrow transplant recipients. J Clin Virol 2020;128:104421.

13 Frobert E, Burrel S, Ducastelle-Lepretre $\mathrm{S}$, et al. Resistance of herpes simplex viruses to acyclovir: an update from a ten-year survey in France. Antiviral Res 2014;111:36-41.

14 Chakrabarti S, Pillay D, Ratcliffe D, et al. Resistance to antiviral drugs in herpes simplex virus infections among allogeneic stem cell transplant recipients: risk factors and prognostic significance. J Infect Dis 2000;181:2055-8.

15 Darville JM, Ley BE, Roome AP, et al. Acyclovir-resistant herpes simplex virus infections in a bone marrow transplant population. Bone Marrow Transplant 1998:22:587-9.

16 Bryant P, Sasadeusz J, Carapetis J, et al. Successful treatment of foscarnet-resistant herpes simplex stomatitis with intravenous cidofovir in a child. Pediatr Infect Dis J 2001;20:1083-6

17 Pereira MR, Pouch SM, Scully B. Infections in allogeneic stem cell transplantation. Principles and Practice of Transplant Infectious Diseases 2018:209-26.

18 Junghanss C, Marr KA, Carter RA, et al. Incidence and outcome of bacterial and fungal infections following nonmyeloablative compared with myeloablative allogeneic hematopoietic stem cell transplantation: a matched control study. Biol Blood Marrow Transplant 2002:8:512-20.

Copyright 2021 BMJ Publishing Group. All rights reserved. For permission to reuse any of this content visit

https://www.bmj.com/company/products-services/rights-and-licensing/permissions/

BMJ Case Report Fellows may re-use this article for personal use and teaching without any further permission.

Become a Fellow of BMJ Case Reports today and you can:

- Submit as many cases as you like

- Enjoy fast sympathetic peer review and rapid publication of accepted articles

- Access all the published articles

Re-use any of the published material for personal use and teaching without further permission

Customer Service

If you have any further queries about your subscription, please contact our customer services team on +44 (0) 2071111105 or via email at support@bmj.com.

Visit casereports.bmj.com for more articles like this and to become a Fellow 